\title{
artigo
}

Brito, R.S.; Ferreira, S.M.I.L.;

Riscos ocupacionais entre os profissionais de saúde do serviço de atendimento movél de urgência: uma revisão integrativa

\section{Riscos ocupacionais entre os profissionais de saúde do serviço de atendimento movél de urgência: uma revisão integrativa}

Occupational risks among healthcare professionals in the mobile emergency service: an integrative review Riesgos ocupacionales de los profesionales de la salud en el servicio de emergencia móvil: una revisión integrativa

\section{RESUMO}

Objetivo: analisar o que tem sido publicado na literatura nacional sobre os riscos ocupacionais que os profissionais do SAMU estão expostos. Método: Trata-se de uma revisão integrativa, cuja busca ocorreu na Biblioteca Virtual em Saúde e no Google Acadêmico, sendo selecionados 11 artigos publicados entre 2011 a 2020. Resultados: Identificou-se os riscos físicos como 0 barulho da sirene e alta temperatura; químicos, poeira e gases; biológicos, contato com sangue, secreções e vômitos; ergonômicos, levantamento de peso e postura inadequada; psicossocial, estresse e fadiga mental. Alguns fatores contribuem para estes agravos, como o número insuficiente de trabalhadores, sobrecarga de trabalho, jornadas fatigantes, desgaste físico, emocional e estresse. Conclusão: Os artigos analisados evidenciaram que os profissionais de saúde que atuam no SAMU devido à natureza do seu trabalho, estão constantemente expostos a riscos ocupacionais.

DESCRITORES: Riscos ocupacionais; Pessoal de Saúde; Serviços Médicos de Emergência.

\section{ABSTRACT}

Objective: to analyze what has been published in the national literature on occupational risks that SAMU professionals are exposed to. Method: This is an integrative review, whose search took place in the Virtual Health Library and Google Scholar, with 11 articles published between 2011 and 2020 being selected. Results: Physical risks such as siren noise and high temperature were identified; chemicals, dust and gases; biological, contact with blood, secretions and vomiting; ergonomic, weight lifting and inadequate posture; psychosocial, stress and mental fatigue. Some factors contribute to these problems, such as the insufficient number of workers, work overload, stressful hours, physical and emotional exhaustion and stress. Conclusion: The analyzed articles showed that health professionals who work at SAMU due to the nature of their work, are constantly exposed to occupational risks.

DESCRIPTORS: Occupational risks; Health Personnel; Emergency Medical Services.

\section{RESUMEN}

Objetivo: analizar lo publicado en la literatura nacional sobre los riesgos laborales a los que están expuestos los profesionales del SAMU. Método: Se trata de una revisión integradora, cuya búsqueda se realizó en la Biblioteca Virtual en Salud y Google Scholar, seleccionándose 11 artículos publicados entre 2011 y 2020. Resultados: Se identificaron riesgos físicos como ruido de sirena y alta temperatura; productos químicos, polvo y gases; biológico, contacto con sangre, secreciones y vómitos; ergonomía, levantamiento de pesas y postura inadecuada; psicosocial, estrés y fatiga mental. Algunos factores contribuyen a estos problemas, como el número insuficiente de trabajadores, la sobrecarga de trabajo, las horas estresantes, el agotamiento físico y emocional y el estrés. Conclusión: Los artículos analizados mostraron que los profesionales de la salud que laboran en SAMU por la naturaleza de su trabajo, están constantemente expuestos a riesgos laborales.

DESCRIPTORES: Riesgos laborales; Personal de salud; Servicios médicos de emergência.

RECEBIDO EM: 21/01/2021 APROVADO EM: 01/02/2021

\section{Rayane Silva Brito}

Discente do Mestrado Profissional no Programa de Pós-Graduação em Enfermagem da Universidade Estadual de Santa Cruz. Enfermeira. ORCID: 0000-0002-7480-3434 


\section{Sônia Maria Isabel Lopes Ferreira}

Docente do curso de Enfermagem da Universidade Estadual de Santa Cruz. Enfermeira. Doutora em Desenvolvimento e Meio Ambiente. ORCID: 0000-0002-8560-019X

\section{INTRODUÇÃO}

0 Serviço de Atendimento Móvel de Urgência (SAMU) é um serviço brasileiro de atendimento às urgências pré-hospitalares, cuja finalidade é propiciar assistência às pessoas em situações de urgência e emergência de natureza clínica, cirúrgica, traumática, obstétrica, pediátrica, psiquiátrica, entre outras, que possa levar ao sofrimento, a complicações ou mesmo à morte, conectando as vítimas aos recursos que necessitam com maior brevidade possível ${ }^{1}$.

Este atendimento do SAMU é executado por equipes de Suporte Básico de Vida (SBV) e de Suporte Avançado de Vida (SAV). As equipes de SBV são compostas por condutores e técnicos de enfermagem, os quais realizam atividades não invasivas, como: à abordagem inicial da vítima, cuidados básicos de ventilação e circulação, imobilização e transporte aos serviços de emergência ${ }^{2}$. Já as equipes de $S A V$, por sua vez, são compostas por condutores, enfermeiros e médicos, que executam procedimentos invasivos de suporte ventilatório e circulatório, bem como realizam transporte de pacientes entre hospitais, denominado transporte medicalizado ${ }^{2}$.

Além disso, vale dizer que o atendimento pré-hospitalar ocorre em residências, locais de trabalho ou em vias públicas, de maneira a estabilizar o quadro clínico do paciente, até que esse chegue ao hospital, contribuindo significativamente com a redução no número de óbitos, ou evitando um agravamento das vítimas acometidas por alguma intercorrência ${ }^{3}$.

Nesse contexto, devido as características dos atendimentos, esses profissionais estão constantemente expostos a diferentes riscos ocupacionais, que são compreendidos como uma ou mais condições do processo de trabalho com o potencial necessário para causar danos, rompendo com o equilíbrio físico, mental e social dos trabalhadores ${ }^{4}$. Dentre esses riscos, estão o risco físico, quando o profissional fica exposto aos agentes explosivos, radiações, temperaturas extremas, ruídos e vibrações; risco químico, quando entra em contato com gases ou vapores, fumos, névoas, produtos tóxicos; risco de acidente, refere-se à situações como espaço limitado e acomodação física da ambulância, iluminação inadequada, falta de proteção, incêndio ou explosão, ferramentas, máquinas ou equipamentos inadequados ou com defeitos; risco biológico, quando em contato com excretas, saliva, vômito, sangue, secreção e líquido pleural ou amniótico; risco psicossocial, relaciona-se com estresse, fadiga, ritmo acelerado, trabalhos em turnos alternados, jornada de trabalho prolongada, prejuízo na inter-relação com chefia e/ ou com colegas de trabalho, entre outros, e risco ergonômico, que caracteriza-se por movimentos bruscos e repetitivos, a exemplo de peso excessivo, posições incômodas e prolongadas, etc ${ }^{5}$.

Tendo em vista esses riscos, os profissionais de saúde que atuam no atendimento pré-hospitalar enfrentam a complexidade e a invisibilidade do atendimento prestado ao usuário, lidam com situações de difícil acesso às vítimas, falta de segurança na cena do acidente, espaço diminuído para realizar procedimentos e manobras, tanto com o veículo parado como em movimento, falta de higiene, presença de animais, pessoas agressivas, tumultos sociais e falta de protocolos exclusivos para prevenção e controle de infecção ${ }^{6}$. Essas situações vivenciadas pelos profissionais de saúde, podem causar-lhes adoecimento e/ou acidentes de trabalho. Considera-se acidente de trabalho quando existe uma colisão entre pessoa e um objeto agressor causando danos corporais acarretando em longo prazo doenças ocupacionais ${ }^{7}$. Esses acidentes geram uma preocupação constante para trabalhadores, em especial os que atuam diretamente com riscos biológicos e químicos, por essa exposição está ligada à infecção por agente patogênico, e é acom- panhada de traumas psicológicos e físicos, podendo causar invalidez ou óbito?

Considerando essas questões, este estudo justifica-se pela necessidade de se aprofundar o conhecimento sobre os riscos ocupacionais a que estão expostos os profissionais de saúde que atuam no SAMU, por lidarem com situações que os expõem a diversos tipos de riscos nos seus processos de trabalho. Assim, este estudo tem como objetivo: analisar na literatura nacional o que tem sido publicado sobre os riscos ocupacionais que os profissionais de saúde do SAMU estão expostos.

\section{MÉTODO}

Trata-se de uma revisão integrativa, esse tipo de estudo é o que dentre os subtipos da revisão de literatura, observa os estudos desenvolvidos por diferentes metodologias em um período definido, gerando a oportunidade dos pesquisadores conhecerem a produção referente a um tema específico e analisá-lo por diversas perspectivas numa percepção ampliada do conhecimento . $^{8}$

Este estudo norteou-se pelas 6 etapas que consiste a revisão integrativa: primeira - identificação do tema e seleção da hipótese ou questão de pesquisa para a elaboração da revisão; segunda etapa - estabelecimento de critérios para inclusão e exclusão de estudos; terceira etapa - definição das informações a serem extraídas dos estudos selecionados/categorização dos estudos; quarta etapa - avaliação dos estudos incluídos na revisão integrativa, quinta etapa - interpretação dos resultados e a sexta etapa - apresentação da revisão/síntese do conhecimento?.

$\mathrm{Na}$ primeira etapa, foi elencada a questão norteadora: o que tem sido publicado sobre os riscos ocupacionais a que os profissionais de saúde do SAMU estão expostos? Na segunda etapa, definiu-se os critérios de inclusão: artigos em idioma inglês, português ou espanhol e que abordavam a temática proposta. É importante assinalar 


\section{artigo}

Brito, R.S.; Ferreira, S.M.I.L.;

Riscos ocupacionais entre os profissionais de saúde do serviço de atendimento movél de urgência: uma revisão integrativa

que não se estabeleceu marco temporal, pois se evidenciou a baixa produção científica sobre o tema. Dessa forma, foram excluídos artigos duplicados, trabalho de conclusão de curso (monografia, dissertação e tese), citações, revisões, não encontrados e outros (resumos de anais, editais, editorial, manual, carta ao editor) também não encontrados, bem como estudos com outros profissionais e serviços.

Os dados foram coletados entre março a maio de 2020. A busca dos estudos foi realizada por meio da pesquisa on-line nas bases de dados: Biblioteca Virtual em Saúde (BVS) e Google Acadêmico. Elencou-se essas bases pelo fato do SAMU ser um serviço com características especificas do Brasil, logo ao realizar a busca na Pub- med e ScienceDirect percebeu-se que os artigos não condiziam com o objeto de estudo. Para proceder com a busca, utilizou-se o descritor "Risco ocupacional", que é indexado nos Descritores em Ciências da Saúde (DeCS) e a palavra-chave "SAMU". A estratégia de busca consistiu no seguinte cruzamento: "Risco ocupacional" AND "SAMU".

A busca foi validada por duas pesquisadoras que analisaram de forma independente os 402 estudos encontrados, após a avaliação foi realizada uma conferencia das decisões de inclusão e exclusão, os casos de divergência foram discutidos e definidos pelas pesquisadoras. Sendo assim, 34 foram excluídos por estarem duplicados, 333 após a leitura do título e resumo por
Figura 1 - Fluxograma da identificação e processo de seleção dos estudos selecionados para compor a revisão integrativa da literatura. Bahia, BA, Brasil, 2020.
Registros identificados na BVS ( $n=173$ )
Registros identificados no google academico $(n=229)$

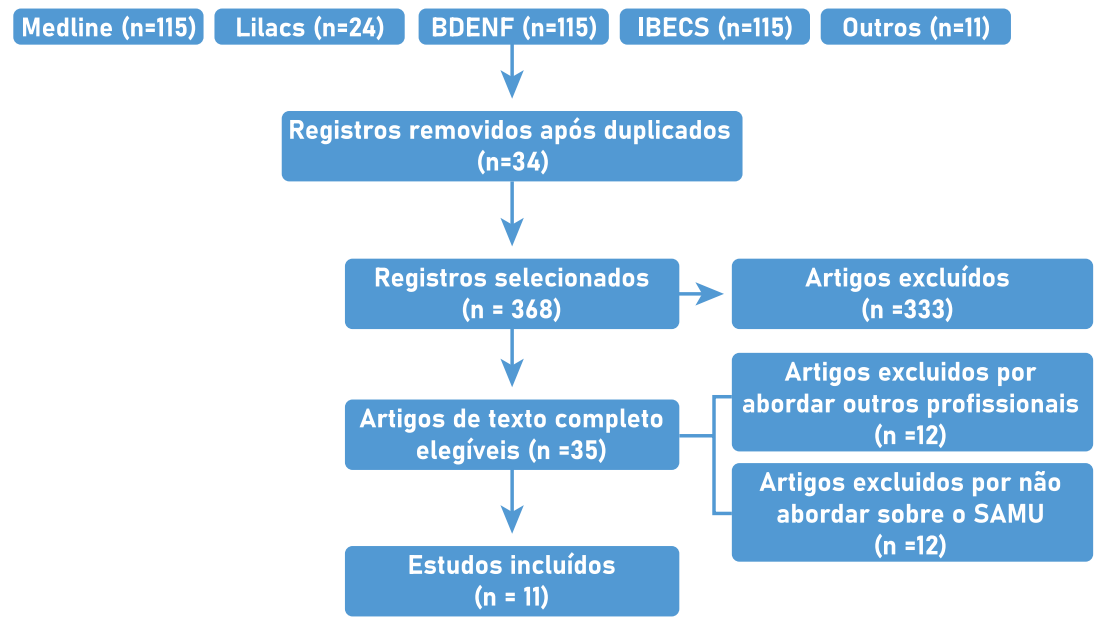

Fonte: Dados da pesquisa (2020). não atenderem aos critérios de inclusão, sendo selecionados para análise 35 estudos, resultando na inclusão de 11 artigos conforme figura 1 .

$\mathrm{Na}$ terceira etapa, foi elaborado uma planilha com as informações a serem extraídas: base de dados, autor, título, revista, ano de e publicação, país, idioma, objetivo, delineamento, instrumentos, população, resultados (tipos de riscos ocupacionais e uso/disponibilidade de equipamento de proteção individual (EPI)) e conclusão. A quarta etapa consistiu no preenchimento da planilha e avaliação dos estudos, para as análises dos dados, os resultados foram separados por tipo de risco, uso e disponibilidade de EPI, a quinta etapa se baseou na interpretação dos resultados, fundamentado na literatura e, por fim, a sexta etapa voltou-se à apresentação desta revisão.

\section{RESULTADOS}

Dos 11 estudos selecionados, observou-se que todos têm como país de publicação o Brasil, com predominância do idioma português, que os sujeitos das pesquisas foram médicos, enfermeiros e técnicos de enfermagem, e que a idade dos participantes foi de 20 a 50 anos, com tempo de serviço no SAMU variando de 1 a 15 anos. Os estudos que compuseram a amostra tiveram como delineamento oito estudos descritivos, seis quantitativos, cinco qualitativos, três transversais, quatro exploratórios e um analítico, os instrumentos utilizados para a coleta de dados foram questionário estruturado e roteiro semiestruturado (QUADRO 1).

Quadro 1 - Caracterização dos estudos incluídos na revisão integrativa. ( $\mathrm{n=11)}$.

\begin{tabular}{|c|c|c|c|c|c|c|c|c|}
\hline \multirow{2}{*}{ AUTOR E ANO } & \multirow{2}{*}{\begin{tabular}{c} 
IDIOMA \\
\cline { 3 - 7 }
\end{tabular}} & N & $\begin{array}{c}\text { IDADE } \\
\text { MÉDIA }\end{array}$ & SEXO & PROFISSÃO & $\begin{array}{c}\text { TEMPO DE } \\
\text { SERVIÇO } \\
\text { (ANOS) }\end{array}$ & DELINEAMENTO & $\begin{array}{c}\text { INSTRUMENTO } \\
\text { UTILIZADO }\end{array}$ \\
\hline $2016^{10}$ & Português & 69 & 40 a 49 & $\begin{array}{c}\text { M-36 } \\
\text { F-33 }\end{array}$ & $\begin{array}{c}\text { Med.-20 } \\
\text { Enf.-16 } \\
\text { Téc.-33 }\end{array}$ & $\begin{array}{c}\text { Maioria } \\
10 \text { a } 14\end{array}$ & $\begin{array}{c}\text { Transversal, } \\
\text { descritivo, quan- } \\
\text { titativo }\end{array}$ & $\begin{array}{c}\text { Questionário } \\
\text { estruturado }\end{array}$ \\
\hline
\end{tabular}




\begin{tabular}{|c|c|c|c|c|c|c|c|c|}
\hline $\begin{array}{l}\text { Nascimento; } \\
\text { Araújo, 2017 }\end{array}$ & Português & 14 & 30 a 45 & $\begin{array}{l}\text { M-6 } \\
\text { F-8 }\end{array}$ & $\begin{array}{l}\text { Enf.- } 4 \\
\text { Téc.- } 10\end{array}$ & $4 \mathrm{a} 13$ & $\begin{array}{l}\text { Descritivo, quali- } \\
\text { tativo }\end{array}$ & $\begin{array}{c}\text { Roteiro } \\
\text { semiestruturado }\end{array}$ \\
\hline $\begin{array}{l}\text { Meireles et al., } \\
2018^{3}\end{array}$ & Português & 22 & $\begin{array}{l}\text { Média } \\
36\end{array}$ & $\begin{array}{l}\text { M-9 } \\
\text { F-13 }\end{array}$ & $\begin{array}{l}\text { Enf.-7 } \\
\text { Téc.-15 }\end{array}$ & $\begin{array}{l}\text { Média } \\
6\end{array}$ & $\begin{array}{l}\text { Transversal, ana- } \\
\text { lítico, quantitativo }\end{array}$ & $\begin{array}{l}\text { Questionário sócio } \\
\text { demográfico e } \\
\text { profissional; Escala de } \\
\text { Estresse no Trabalho }\end{array}$ \\
\hline $\begin{array}{l}\text { Santos Júnior; } \\
\text { Silveira; Araújo, } \\
2010^{12}\end{array}$ & Português & 100 & $\begin{array}{c}\text { Maioria } 3 \\
6 \text { a } 45\end{array}$ & $\begin{array}{l}M-24 \\
\text { F-76 }\end{array}$ & $\begin{array}{l}\text { Enf.-25 } \\
\text { Téc.-57 } \\
\text { Aux.-18 }\end{array}$ & $\begin{array}{l}\text { Maioria } \\
5\end{array}$ & $\begin{array}{c}\text { Transversal, } \\
\text { exploratório, } \\
\text { descritivo, quan- } \\
\text { titativo }\end{array}$ & $\begin{array}{l}\text { Questionário } \\
\text { estruturado }\end{array}$ \\
\hline $\begin{array}{l}\text { Castro; Almeida, } \\
\text { Mussi, 2018 }\end{array}$ & Português & 4 & $\begin{array}{c}\text { Média } \\
32\end{array}$ & $\begin{array}{l}\mathrm{M}-2 \\
\mathrm{~F}-2\end{array}$ & $\begin{array}{l}\text { Enf.-2 } \\
\text { Téc.-2 }\end{array}$ & 3 a 6 & $\begin{array}{c}\text { Exploratório, } \\
\text { qualitativo }\end{array}$ & $\begin{array}{c}\text { Roteiro } \\
\text { semiestruturado }\end{array}$ \\
\hline $\begin{array}{l}\text { Silva et al., } \\
2019^{14}\end{array}$ & Português & 18 & $\begin{array}{l}\text { Maioria } \\
20 \text { a } 29\end{array}$ & $\begin{array}{l}\mathrm{M}-11 \\
\mathrm{~F}-7\end{array}$ & $\begin{array}{l}\text { Enf.-7 } \\
\text { Téc.-11 }\end{array}$ & $\begin{array}{l}\text { Maioria } \\
10 \text { a } 11\end{array}$ & $\begin{array}{l}\text { Exploratório, des- } \\
\text { critivo qualitativo }\end{array}$ & $\begin{array}{l}\text { Questionário estrutu- } \\
\text { rado; Questionário para } \\
\text { identificação preliminar } \\
\text { da Burnout; Maslach } \\
\text { Burnout Inventary }\end{array}$ \\
\hline $\begin{array}{l}\text { Mafra et al., } \\
2008^{15}\end{array}$ & Português & 12 & $\begin{array}{l}\text { Maioria } \\
41 \text { a } 50\end{array}$ & $\begin{array}{l}M-4 \\
F-8\end{array}$ & Enf.-12 & $\begin{array}{l}\text { Maioria } \\
3 \text { e } 4\end{array}$ & $\begin{array}{l}\text { Exploratório, des- } \\
\text { critivo, qualitativo }\end{array}$ & $\begin{array}{c}\text { Questionário } \\
\text { semiestruturado }\end{array}$ \\
\hline $\begin{array}{l}\text { Melo et al., } \\
2016^{16}\end{array}$ & Português & 60 & - & $\begin{array}{l}M-25 \\
F-35\end{array}$ & $\begin{array}{l}\text { Med-20 } \\
\text { Enf.-20 } \\
\text { Téc.-20 }\end{array}$ & - & $\begin{array}{l}\text { Descritivo, explo- } \\
\text { ratório, quanti- } \\
\text { tativo }\end{array}$ & $\begin{array}{l}\text { Questionário } \\
\text { estruturado }\end{array}$ \\
\hline $\begin{array}{l}\text { Alves et al., } \\
2013^{17}\end{array}$ & Inglês & 12 & $\begin{array}{l}\text { Maioria } \\
21 \text { a } 30\end{array}$ & $\begin{array}{l}\text { Maioria } \\
\text { feminino }\end{array}$ & Enf.-12 & $\begin{array}{c}\text { Maioria } \\
10\end{array}$ & $\begin{array}{l}\text { Descritivo, quali- } \\
\text { tativo }\end{array}$ & $\begin{array}{c}\text { Roteiro } \\
\text { semiestruturado }\end{array}$ \\
\hline $\begin{array}{l}\text { Carvalho et al., } \\
2020^{18}\end{array}$ & Inglês & 203 & $\begin{array}{l}\text { Maioria } \\
40 \text { a } 44\end{array}$ & $\begin{array}{l}M-47 \\
F-156\end{array}$ & $\begin{array}{c}\text { Enf.-56 } \\
\text { Téc.-139 } \\
\text { Aux.-8 }\end{array}$ & $\begin{array}{l}\text { Maioria } \\
1 \text { a } 5\end{array}$ & $\begin{array}{l}\text { Descritivo, quan- } \\
\text { titativo }\end{array}$ & $\begin{array}{c}\text { Questionário sociode- } \\
\text { mográfico e Inventário } \\
\text { de Sintomas de Stress } \\
\text { de Lipp }\end{array}$ \\
\hline $\begin{array}{c}\text { Guimarães et } \\
\mathrm{al}^{19}\end{array}$ & Português & 5 & - & - & Téc.-5 & - & Qualitativo & $\begin{array}{c}\text { Roteiro } \\
\text { semiestruturado }\end{array}$ \\
\hline
\end{tabular}

Após a leitura minuciosa dos 11 artigos encontrados foi possível agrupá-los por similaridade de conteúdo constituindo duas categorias de análise: tipos de riscos ocupacionais e uso e disponibilidade do EPI. Com relação a primeira categoria denomi- nada tipos de riscos ocupacionais, com 11 artigos descritos nos Quadros 2 e 3, sendo que: três estudos abordaram riscos físicos; riscos ergonômicos abordados em três estudos, riscos biológicos também abordados em três estudos; os riscos químicos em quatro; acidentes em cinco estudos e o psicossocial em 11.

No que corresponde a segunda categoria intitulada uso e disponibilidade do EPI, foram compilados 06 artigos os quais abordaram a temática, apresentados no Quadro 4.

Quadro 2 - Síntese dos estudos incluídos na revisão. $(n=11)$.

\begin{tabular}{|c|c|c|c|c|}
\hline \multirow{2}{*}{ AUTOR } & \multicolumn{4}{|c|}{ RISCOS } \\
\hline & Físıco & ERGONÔMICO & BIOLÓGICO & QUÍMICO \\
\hline Leite et al. ${ }^{10}$ & $\begin{array}{c}87 \% \text { ruídos da sirene } \\
81,2 \% \text { temperatura } \\
\text { elevada }\end{array}$ & $\begin{array}{c}79,7 \% \text { levantamento de peso } \\
73,9 \% \text { postura inadequada } \\
62,3 \% \text { esforço físico }\end{array}$ & $\begin{array}{l}89,9 \% \text { sangue } \\
79,7 \% \text { saliva } \\
78,3 \% \text { vômito }\end{array}$ & $\begin{array}{l}63,8 \% \text { poeira } \\
44,9 \% \text { gases }\end{array}$ \\
\hline Nascimento; Araújo11 & $\begin{array}{l}\text { 42,8\% relatam } \\
\text { exposição }\end{array}$ & 50\% relatam exposição & $71,4 \%$ relatam exposição & $\begin{array}{l}\text { 34,7\% relatam } \\
\text { exposição }\end{array}$ \\
\hline Meireles et al. ${ }^{3}$ & - & - & - & - \\
\hline $\begin{array}{c}\text { Santos Júnior; Silveira; } \\
\text { Araújo }\end{array}$ & - & $65,1 \%$ fadiga muscular & - & - \\
\hline
\end{tabular}




\section{artigo}

Brito, R.S.; Ferreira, S.M.I.L

Riscos ocupacionais entre os profissionais de saúde do serviço de atendimento movél de urgência: uma revisão integrativa

\begin{tabular}{|c|c|c|c|c|}
\hline Castro; Almeida; Mussi ${ }^{13}$ & - & - & - & - \\
\hline Silva et al. ${ }^{14}$ & - & - & - & - \\
\hline Mafra et al. ${ }^{15}$ & - & - & $\begin{array}{l}25 \% \text { contato com sague, } \\
\text { com secreção e saliva }\end{array}$ & $\begin{array}{l}\text { 8,33\% água } \\
\text { contaminada }\end{array}$ \\
\hline Melo et al. ${ }^{16}$ & - & - & - & - \\
\hline Alves et al. ${ }^{17}$ & $\begin{array}{l}\text { 8,33\% mudanças } \\
\text { climáticas }\end{array}$ & - & - & - \\
\hline Carvalho et al. ${ }^{18}$ & - & - & - & - \\
\hline Guimarães et al ${ }^{19}$ & - & - & $\begin{array}{l}\text { contato com sangue, se- } \\
\text { creção e fluidos corporais }\end{array}$ & produtos químicos \\
\hline
\end{tabular}

\section{Quadro 3 - Síntese dos estudos incluídos na revisão sobre riscos de acidente e psicossocial. (n=11)}

\begin{tabular}{|c|c|c|}
\hline \multirow{2}{*}{ AUTOR } & \multicolumn{2}{|r|}{ RISCOS } \\
\hline & DE ACIDENTE & PSICOSSOCIAL \\
\hline Leite et al. ${ }^{10}$ & 79,7\% colisão de automóveis & $82,6 \%$ estresse $62,3 \%$ trabalho noturno \\
\hline $\begin{array}{l}\text { Nascimento; } \\
\text { Araújo }^{11}\end{array}$ & 35,7\% relatam exposição & $50 \%$ relatam exposiç̧ão \\
\hline Meireles et al. ${ }^{3}$ & - & $45,50 \%$ possuem alto estresse \\
\hline $\begin{array}{l}\text { Santos Júnior; } \\
\text { Silveira; Araújo }{ }^{12}\end{array}$ & - & $61,9 \%$ fadiga mental $67 \%$ jornada de trabalho prolongada (>60h semanal) \\
\hline $\begin{array}{l}\text { Castro; Almeida; } \\
\text { Mussi }^{13}\end{array}$ & - & $\begin{array}{l}\text { Prejuízo na inter-relação com colegas de trabalho, gestores municipais, } \\
\text { pacientes e acompanhantes (humilhação, falta de respeito e ameaça) }\end{array}$ \\
\hline Silva et al. ${ }^{14}$ & - & $\begin{array}{c}\text { 38,9\% nível moderado e 16,7\% nível alto de exaustão emocional 77,8\% } \\
\text { nível moderado de despersonalização 100\% nível alto de reduzida reali- } \\
\text { zação profissional 78\% jornada de trabalho prolongada (>60 horas) } 22,2 \% \\
\text { possibilidade de desenvolver Síndrome Burnout }\end{array}$ \\
\hline Mafra et al. ${ }^{15}$ & $\begin{array}{l}\text { 16,66\% relatam exposição (acidentes } \\
\text { com ferragens e iluminação inadequada) }\end{array}$ & 16,66\% relatam exposição (situações estressantes) \\
\hline Melo et al. ${ }^{16}$ & - & $16,66 \%$ relatam carga de trabalho $>60 \mathrm{~h}$. \\
\hline Alves et al. ${ }^{17}$ & $\begin{array}{l}16,66 \% \text { relatam exposição (acidentes } \\
\text { automobilísticos em rodovias) }\end{array}$ & $\begin{array}{c}\text { 33,33 \% relatam exposição (situação de estresse população agressiva, } \\
\text { elevada tensão ambiental - troca de tiro, agressão, conflito na relação } \\
\text { Interprofissional SAMU x hospital) }\end{array}$ \\
\hline Carvalho et al. ${ }^{18}$ & $\begin{array}{l}\text { 48,66\% relatam exposição (instalação } \\
\text { física inadequada) 77,83\% relatam } \\
\text { exposição (ambiente de trabalho } \\
\text { insalubre) }\end{array}$ & $\begin{array}{c}\text { 24,6\% relataram estrese (19,7\% fase de resistência, 4,4\% exaustão, 0,5 } \\
\text { quase exaustão) } 63,05 \% \text { relatam desgaste emocional com o trabalho que } \\
\text { desempenha }\end{array}$ \\
\hline Guimarães et al ${ }^{19}$ & - & - \\
\hline
\end{tabular}

\section{Quadro 4 - Síntese dos estudos incluídos na revisão que abordaram o equipamento de proteção individual. $(\mathrm{n}=6)$.}

\begin{tabular}{|c|c|c|}
\hline \multirow{2}{*}{ AUTOR } & \multicolumn{2}{|c|}{ EQUIPAMENTO DE PROTEÇÃO INDIVIDUAL (EPI) } \\
\hline & USO & DISPONIBILIDADE \\
\hline Leite et al. ${ }^{10}$ & $\begin{array}{l}100 \% \text { macacão somente; } 85,5 \% \text { luvas; } 84,1 \% \\
\text { máscara; } 69,6 \% \text { botas; } 40,6 \% \text { óculos; } 23,2 \% \text { gor- } \\
\text { ros e somente; } 10,1 \% \text { todos os tipos de } E P I ;\end{array}$ & - \\
\hline Nascimento; Araújo ${ }^{11}$ & $50 \%$ EPI em geral & $14,3 \%$ falta de EPI \\
\hline
\end{tabular}




\begin{tabular}{|c|c|c|}
\hline $\begin{array}{l}\text { Santos Júnior; Silvei- } \\
\text { ra; Araújo }\end{array}$ & $\begin{array}{c}95 \% \text { EPI em geral } \\
66 \% \text { luva, máscara e botas } \\
34 \% \text { luva, máscara, botas e macacão }\end{array}$ & - \\
\hline Mafra et al. ${ }^{15}$ & $\begin{array}{c}100 \% \text { botas } \\
100 \% \text { luvas } \\
100 \% \text { macacão } \\
41,6 \% \text { máscaras } \\
16,6 \% \text { óculos }\end{array}$ & Minoria relatam faltar material adequado \\
\hline Melo et $\mathrm{al}^{16}$ & $\begin{array}{c}100 \% \text { EPI em geral } \\
48,3 \% \text { todos os EPIs } \\
\text { (macacão, luva, óculos, máscara e botas) }\end{array}$ & $100 \%$ referiram que sempre encontram os EPIs disponíveis \\
\hline Guimarães et al. ${ }^{19}$ & $\begin{array}{l}\text { Relatam uso dos EPIs } \\
\text { (luvas, botas e macacão) }\end{array}$ & $\begin{array}{c}\text { Relatam que o serviço só fornece luvas de procedimento aos } \\
\text { profissionais }\end{array}$ \\
\hline
\end{tabular}

\section{DISCUSSÃO}

\section{Tipos de riscos ocupacionais}

Os riscos físicos foram mencionados em apenas $3 \operatorname{artigos}^{10,11,17}$, sendo que no estudo de Nascimento e Araújo ${ }^{11}$ não foi especificado o tipo de exposição, no de Alves et al. ${ }^{17}$ foi apresentada a exposição a mudanças climáticas, e Leite et al. ${ }^{10}$ apontaram ruídos da sirene da ambulância e temperatura elevada. Os riscos físicos mencionados corroboram com o estudo realizado por Costa et al. ${ }^{20}$, no qual os ruídos do trânsito e da sirene foram considerados como os que têm maior potencial de causar acidentes no ambiente pré-hospitalar. Como medida de prevenção aos problemas auditivos, dos profissionais que atuam em unidades de suporte móveis, recomenda-se que sejam submetidos a exames periódicos de audiometria, além da utilização de EPI equivalente ${ }^{20}$.

Os riscos ergonômicos apresentados neste estudo, foram: levantamento de peso, postura inadequada e a fadiga muscular ${ }^{10,12}$. Além desses, o estudo de Nascimento e Araújo ${ }^{11}$ salientou a exposição ao risco ergonômico, porém não citou as situações. É válido ressaltar que os riscos ergonômicos são frequentes em socorristas que atuam no atendimento pré-hospitalar, de modo que o esforço físico exigido durante a movimentação e remoção de pacientes influenciam decisivamente para o surgimento de dores musculares, que podem causar problemas posturais, fadiga, hérnias, fraturas, torções, contusões, lombalgias e varizes ${ }^{21}$.
A respeito dos riscos biológicos encontrados constatou-se: contato com sangue, vômito, saliva, secreções e fluídos corporais $^{10,11,15,19}$. Esse tipo de risco varia conforme as diferentes categorias profissionais, as atividades realizadas pelo profissional e os setores de atuação dentro dos serviços de saúde. Assim, segundo Fernandes et al. ${ }^{7}$, os profissionais mais expostos são aqueles que lidam diretamente com pacientes, realizando procedimentos invasivos de diferentes graus de complexidade, sofrendo exposição ocupacional acidental através do sangue ou fluídos corporais. Esses profissionais correm risco de infecção a inúmeros patógenos, sendo os vírus da imunodeficiência humana, hepatite $\mathrm{B}$ ou $\mathrm{C}$ considerados os de maior relevância, dado sua prevalência entre pacientes ${ }^{22}$.

Vale dizer que alguns fatores atuam como predisponentes para o risco biológico: número insuficiente de trabalhadores, a sobrecarga de trabalho, jornadas fatigantes, continuidade da assistência em turnos e plantões noturnos, desgaste físico e emocional, capacitação técnica deficiente, falta de atenção, excesso de confiança, utilização de materiais inadequados, estresse e a não adoção das medidas de precauções padrão ${ }^{23}$.

No que tange aos riscos químicos, observou-se neste estudo: poeira gases, água contaminada e produtos químicos ${ }^{10,11,15,19}$. A exposição a agentes químicos é responsável por $80 \%$ das dermatoses ocupacionais, além disso pode causar queimaduras, cefaleia, asma brônquica, doenças neurológicas, renais, hepáticas, gástricas e intestinais, entre outras. Tais agentes estão habitualmente no ambiente de trabalho na forma de gases, poeiras, fumos, vapores, neblinas e névoas ${ }^{24}$.

Em relação aos riscos de acidente, identificou-se: colisão de automóveis, acidente com ferragens, iluminação inadequada, instalação física inadequada e ambiente de trabalho insalubre $^{10,11,15,17,18}$. Os acidentes de trânsito envolvendo a ambulância e outros veículos são considerados frequentes na prática laboral desses profissionais, desencadeados principalmente pelo trânsito, assim como, a incompreensão da população acerca da necessidade de deslocamento rápido das ambulâncias. A brevidade da chegada da ambulância ao local do acidente é fundamental para o bom prognóstico do paciente, entretanto a alta velocidade, coloca a equipe em risco de acidente, devido as particularidades do trabalho dentro da ambulância, que apresenta espaço limitado, com pouca ventilação, dinâmica dos movimentos de tráfego e curvas acentuadas ${ }^{25}$.

Por último, o risco psicossocial foi citado em todos os trabalhos selecionados, com predominância para o trabalho noturno, jornada de trabalho prolongada, prejuízo na inter-relação com colegas e superiores, situação de estresse com a população, dentre outros $^{3,10-19}$. Para Ueno et al. ${ }^{26}$, o estresse na atividade laboral compromete não só o desempenho produtivo do trabalhador, mas também o equilíbrio físico e emocional, repercutindo em sua vida pessoal. Nesse contexto, existem respostas fisiológicas a diferentes tipos de estressores e cada pessoa tem uma maneira diferente de sentir e interpretar as fontes que provocam o estresse

Esses resultados corroboram com o 


\section{artigo}

Brito, R.S.; Ferreira, S.M.I.L.

Riscos ocupacionais entre os profissionais de saúde do serviço de atendimento movél de urgência: uma revisão integrativa

estudo realizado por Carvalho et al. ${ }^{18}$ sobre os fatores relacionados ao estresse ocupacional da equipe de enfermagem do SAMU em que os participantes relatam fatores relacionados a qualidade do sono, quais sejam, trabalhar em instalações físicas inadequadas, em ambiente insalubre, possuir restrição de autonomia profissional e sentimento de desgaste emocional com o trabalho que desempenha.

Por sua vez, um estudo realizado com médicos, enfermeiros e técnicos de enfermagem atuantes no SAMU, com o objetivo de avaliar o nível de estresse ocupacional dessa equipe, os resultados obtidos indicaram uma alta porcentagem de trabalhadores que não apresentaram estresse, atribuindo esta apuração, principalmente a fatores como: baixa idade, uma vez $62,5 \%$ dos participantes estavam inseridos na faixa etária entre 20 e 30 anos, além de pouco tempo de trabalho no serviço ${ }^{27}$. Assim, o fato de serem jovens pode ter contribuído para que o organismo apresentasse maior resistência aos agentes estressores, obtendo, dessa forma, maior disposição para realizar suas atividades.

\section{EPI}

No Quadro 4 são apresentados o uso e a disponibilidade dos EPIs que foram mencionados em 6 estudos ${ }^{10-12,15,16,19}$. Deste modo, a maioria dos participantes dos estudos relataram o uso de macacão, botas, luvas e óculos, embora quanto a disponibilidade desses equipamentos, em alguns estudos os participantes relataram a falta de destes.
A padronização para o uso de EPIs pelos profissionais do SAMU é estabelecida pelo Manual de Identidade Visual da Rede SAMU 192 e pela Portaria no 2048 de 05 de novembro de 2002, na qual orienta o uso do macacão e botas de uso obrigatório, adicionando a necessidade da máscara cirúrgica, óculos de proteção e luva de procedimento, sobretudo, quando em contato com o paciente ${ }^{1,28}$. Essa padronização não restringe que os serviços possuam características individuais quanto ao uso dos EPIs de acordo ao papel que é desempenhado no atendimento local, desde que sigam as normas regulamentadoras vigentes no país.

$\mathrm{O}$ uso de EPI não elimina todos os riscos aos quais os trabalhadores estão expostos, porém reduz a possibilidade de ocorrer acidentes $^{29}$. Essa é uma das medidas de biossegurança, assegurada pela Norma Regulamentadora 3230 , que tem o objetivo de promover a proteção dos trabalhadores nos serviços de saúde.

O setor de urgência e emergência, tanto no atendimento pré-hospitalar quanto o atendimento hospitalar, é considerado um ambiente insalubre, por abrigar pessoas com diversos tipos de doenças infectocontagiosas e pelos riscos inerentes aos procedimentos realizados pelos profissionais de saúde. Assim, quando adotados os EPIs e utilizados de forma correta, os profissionais evitam grandes complicações com relação a sua saúde ${ }^{31}$.

Por fim, pode-se dizer que o resultado desse estudo, em um grau comparativo, está de acordo com o esperado na literatura e também com o que ocorre no processo de trabalho dos profissionais de saúde que atuam no SAMU. Tais profissionais, ao prestarem assistência direta aos pacientes com graus variados de gravidade, podem sofrer acidentes durante o manuseio de equipamentos, materiais perfurocortantes, preparo e administração de medicamentos, além dos fatores relacionados ao acesso ao local do atendimento como o risco de colisão da ambulância e a relação com a população.

\section{CONCLUSÃO}

Nesta revisão ficou evidente que os profissionais de saúde que atuam no SAMU, pela natureza do seu trabalho, estão constantemente expostos a riscos ocupacionais, tais como: riscos físicos, ergonômicos, biológicos, químicos e psicossocial. Dentre os riscos físicos citados pelos profissionais estão: ruídos da sirene da ambulância e temperatura elevada; os riscos ergonômicos mencionados foram a postura inadequada, levantamento de peso, e a fadiga muscular; os riscos biológicos mais apontados foram: contato com sangue, vômito, saliva, secreções e fluídos corporais; dentre os riscos químicos estão o contato com poeira, gases, água contaminada e produtos químicos e por último o risco psicossocial, no qual houve predominância para o trabalho noturno, jornada de trabalho prolongada, prejuízo na inter-relação com colegas e superiores, situação de estresse com a população, dentre outros.

\section{REFERÊNCIAS}

1. Brasil M da S. Portaria GM/MS No2048, de 5 de Novembro de 2002. Aprova o Regulamento Técnico Dos Sistemas Estaduais de Urgência e Emergência.; 2002.

2. Ferreira AM, Nobre J de OC, Oliveira LFM de, Medeiros SC, Davim RMB, Alves ÉSRC. Serviço de Atendimento Móvel de Urgência: satisfação deusuários. RevenfermUFPEline. 2017;11(10):3724.:10.5205/ reuol.12834-30982-1-SM.1110201703

3. Meireles A dos R, Machado MG, da Silva RM, dos Santos OP, de Moraes Filho IM, Ribeiro FMS e S. Estresse ocupacional da equipe de enfermagem de um serviço de atendimento móvel de urgência. Rev Cient Sena Aires. 2018;7(3):228-234.

4. Bezerra AMF, Bezerra KKS, Bezerra WKT, Athayde ACR, Vieira
AL. Riscos ocupacionais e acidentes de trabalho em profissionais de enfermagem no ambiente hospitalar. Rev Bras Educ e Saúde. 2015;5(2):1-07.

5. Soares RZ, Schoen AS, Benelli K da RG, Araújo MS, Neves M. Análise dos acidentes de trabalho com exposição a material biológico notificados por profissionais da saúde. Rev bras med trab. 2019;17(2):201-208.

6. Araujo LR de A, Moreira MR. Risco ocupacional enfrentado pela equipe de enfermagem do Serviço de Atendimento Móvel de Urgência. Rev Multidiscip e Psicol. 2015;2.

7. Fernandes AT, Nery AA, Matos Filho SA, Morais RLGL, Oliveira J da S, Oliveira YNS. Sentimentos vivenciados por trabalhadores de 
saúde na ocorrência de acidentes com material biológico. Rev Paul Enferm. 2018;29(1):56-67.

8. Soares CB, Hoga LAK, Peduzzi M, Sangaleti C, Yonekura T, Silva DRAD. Revisão integrativa: conceitos e métodos utilizados na enfermagem Revisão integrativa: conceitos e métodos utilizados na enfermagem Artigo de revisão. Rev Esc Enferm USP. 2014;48(2):335-345. doi:10.1590/S0080623420140000200020

9. Mendes KDS, Silveira RC de CP, Galvão CM. Revisão integrativa: método de pesquisa para a incorporação de evidências na saúde e na enfermagem. Texto Context - Enferm. 2008;17(4):758-764. doi:10.1590/s0104-07072008000400018

10. Leite HDCS, Carvalho MTR de, Cariman SL da S, Araújo ER de $M$, Silva NC, Carvalho A de O. Risco ocupacional entre profissionais de saúde do Serviço de Atendimento Móvel de Urgência SAMU. Enferm em Foco. 2016;7(3/4):31-35. doi:10.21675/2357707X.2016.v7.n3/4.912

11. Nascimento MO, Araújo GF. Riscos Ocupacionais dos Profissionais de Enfermagem atuantes no SAMU 192. Id Line Rev Psic. 2017;10(33):212-223. doi:10.14295/idonline.v10i33.614

12. Santos Júnior BJ dos, Silveira CDLS, Araújo EC de. Work conditions and ergonomic factors of health risks to the nursing team of the Mobile Emergency Care - SAMU in Recife-PE city. Rev Enferm UFPE line. 2010;4(1):253. doi:10.5205/reuol.746-5686-5le. 0401201032

13. Castro AP de, Almeida GC, Mussi MVF. Percepções e atitudes de profissionais de enfermagem frente à violência ocupacional: um estudo linguístico no alto sertão paraibano. Rev (Con)Textos Linguísticos. 2018;12(22):79-92.

14. Silva FG da, Andrade ADP, Ponte KMDA, Ferreira VES, Sousa BDS, Gonçalves KG. Predisposição para síndrome de burnout na equipe de enfermagem do Serviço de Atendimento Móvel de Urgência. Enferm em Foco. 2019;10(1):40-45. doi:10.21675/2357-707x.2019.v10.n1.1600

15. Mafra DAL, Santana JCB, Fonseca IC, Silva MP, Viana JX. Percepção dos Enfermeiros sobre a importância do uso dos Equipamentos de Proteção Individual para Riscos Biológicos em um Serviço de Atendimento Móvel de Urgência. O Mundo da Saúde. 2008;32(1):31-38.

16. Melo L da S, Barbosa AMG, Araújo AMG de, Freitas MMS de M, Lima M das GL, Melo L da S. Riscos ocupacionais no Serviço de Atendimento Móvel de Urgência. Rev iberoam educ investi enferm. 2016;6(2):65-72.

17. Alves M, da Rocha TB, Ribeiro HCTC, Gomes GG, Brito MJM. Particularidades do trabalho do enfermeiro no serviço de atendimento móvel de urgência de Belo Horizonte. Texto e Context Enferm. 2013;22(1):208-215. doi:10.1590/S010407072013000100025

18. Carvalho AEL de, Frazão I da S, Silva DMR da, Andrade MS, Vasconcelos SC, Aquino JM de. Estresse dos profissionais de enfermagem atuantes no atendimento pré-hospitalar. Rev Bras Enferm. 2020;73(2). doi:10.1590/0034-7167-2018-0660
19. Guimarães E de A, Araújo GD, Bezerra R, da Silveira RC, de Oliveira VC. Percepção de técnicos de enfermagem sobre o uso de equipamentos de proteção individual em um serviço de urgência. Cienc y Enferm. 2011;17(3):113-123. doi:10.4067/s071795532011000300010

20. Costa IKF, Liberato SMD, Costa IKF, Melo MDM, Simpson CA, de Farias GM. Riscos ocupacionais em um Serviço de Atendimento Móvel de Urgência. J res fundam care. 2013;6(3):938-947. doi:10.9789/2175-5361.2014v6n3p938

21. OLIVEIRA JA do N. Avaliação de riscos ergonômicos nos profissionais de enfermagem do serviço de atendimento móvel de urgência - SAMU/Recife. Published online February 26, 2015. Accessed January 11, 2021. https://repositorio.ufpe.br/handle/123456789/15049

22. Vieira KMR, Vieira Jr FU, Bittencourt ZZL de C. Acidentes de trabalho com material biológico em hospital escola. Rev Bras Enferm. 2019;72(3):737-743. doi:10.1590/0034-7167-2018-0630

23. Azevedo AP de, Oliveira JFS de, Medeiros FP, et al. Acidentes com exposição a material biológico atendidos em um hospital. Rev Enferm UFPE line. 2019;13(0). doi:10.5205/19818963.2019.239025

24. BRASIL. Ministério da saúde. Saúde Do Trabalhador e Da Trabalhadora. Cadernos Da Atenção Básica.; 2018.

25. Goulart LS, Rocha LP, de Carvalho DP, Tomaschewski-Barlem JG, de Lima Dalmolin G, de Pinho EC. Acidentes de trabalho e os riscos ocupacionais identificados no Serviço de Atendimento Móvel de Urgência. Rev da Esc Enferm. 2020;54. doi:10.1590/ S1980-220X2018056903603

26. Ueno LGS, Bobroff MCC, Martins JT, Machado RCBR, Linares PG, Gaspar S de G. Estresse ocupacional: estressores referidos pela equipe de enfermagem. Rev Enferm UFPE Line. 2017;11(4):16321638. doi:10.5205/1981-8963-v11i4a15232p1632-1638-2017

27. Adriano MSPF, de Almeida MR, Ramalho PPL, da Costa IP, do Nascimento ARS, Moraes JCO. Estresse ocupacional em profissionais da saúde que atuam no Serviço de Atendimento Móvel de Urgência de Cajazeiras - PB. Rev. Bras. Cienc. Saúde. https:// periodicos.ufpb.br/index.php/rbcs/article/view/16924/16432. Published 2017.

28. BRASIL M da S. Manual de Identidade Visual SAMU.; 2012.

29. Corrêa LBD, Gomes SCS, Ferreira TF, Caldas A de JM. Fatores associados ao uso de equipamentos de proteção individual por profissionais de saúde acidentados com material biológico no estado do Maranhão. Rev Bras Med Trab. 2017;15(4):340-349.

30. BRASIL. Ministério do trabalho e emprego. Portaria No 485 , de 11 de Novembro de 2005. Aprova a Norma Regulamentadora No 32 (Segurança e Saúde No Trabalho Em Estabelecimentos de Saúde).; 2005.

31. Barbosa ADA, Ferreira AM, Martins E da NX, Bezerra AMF, Bezerra J de AL. Percepção do enfermeiro acerca do uso de equipamentos de proteção individual em hospital paraibano. Rev Bras Educ e Saúde. 2017;7(1):01-08. doi:10.18378/rebes.v7i1.4858 